Original article

\title{
Parameter dynamics of the physical development in children and youth of Volgograd region (Russian Federation) using the percentile method
}

\author{
Valery V. Yatsyshen ${ }^{1}$, Tatyana L. Yatsyshena ${ }^{2}$ \\ ${ }^{1}$ Volgograd State University, Volgograd, Russia \\ ${ }^{2}$ Volgograd State Medical University, Volgograd, Russia
}

Received 27 October 2018, Revised 6 December 2019, Accepted 18 February 2020

(C) 2018, Yatsyshen V.V., Yatsyshena T.L.

Abstract: The study objective was to analyze the parameters of physical development (body length and weight) in children and youth 7-17 yo - students of Volgograd region educational institutions over 2012-2016 using the percentile method.

Material and methods - We examined 4,367 school students, of which 2,056 and 2,311 were boys and girl, correspondingly. The body lengths and weights were assessed by conventional methods. The results were processed using the programs Statistica 6.0 and MATLAB 7. Results - The values of the body length and weight centiles (3, 10, 25, 50, 75, 90 and 97\%) in 7-17 yo girls and boys were computed. It was established that the lowest body length indicators were currently typical for 7 yo boys. Starting at 13 yo, body length indicators in boys were ahead of those for girls. In 15-16 yo girls, growth stabilization was observed, while boys continued growing until the age of 17 yo. All percentile values of body weight in primary school age boys (except for 8 year-olds) were ahead or equivalent to those of girls. At the level of $75-97 \%$ in all age groups, the body mass values in boys were ahead of those in girls. At the age of $16-17$ yo, all percentile values of body weight in boys were higher than in girls. Harmonious physical development was detected in $69.6 \%$ of boys and $61.7 \%$ of girls.

Conclusion - Percentile analysis of body lengths and weights in children and youth of the Volgograd region facilitated the identification of gender-specific characteristics and assessment of harmonious physical development.

Keywords: physical development, somatometric signs, percentile corridors, harmonious development.

Cite as Yatsyshen VV, Yatsyshena TL. Parameter dynamics of the physical development in children and youth of Volgograd region (Russian Federation) using the percentile method. Russian Open Medical Journal 2020; 9: e0104.

Correspondence to Valery V. Yatsyshen. Address: Institute of Priority Technologies, 100, University Avenue, 400062, Volgograd, Russia. Phone: $+7(8442) 465599,+79064020716$. E-mail: valeryyat@gmail.com.

\section{Introduction}

Physical development is among the most important and mandatory health criteria of children and youth. Besides, it is well known that physical development indicators are informative, simple, and easy to determine in order to evaluate children and youth health $[1,2]$. Studying and analyzing morphological and functional parameters in children and adolescents is a very relevant research task, both in Russia and worldwide. To date, substantial empirical data and theoretical material have been collected in this field of study. Moreover, a significant fraction of the authors is in need to develop regional standards necessitating local monitoring of growth and development in children and adolescents. Such standards require periodical updates at different administrative territories of the Russian Federation. Percentile method is one of conventionally used techniques among pediatric practitioners for assessing physical development of children and youth [3]. For Volgograd region, an analysis of the physical development parameters in children and adolescents by percentile method was not yet performed, hence the relevance of our study.

\section{Material and Methods}

Using percentile method, we evaluated major physical development indicators (body length, $\mathrm{cm}$, and body weight, $\mathrm{kg}$ ) in 4,367 school students of the Volgograd region, Russian Federation (2,056 boys and 2,311 girls living in the cities of Volgograd and Volzhsky, as well as in Zhirnovsky, Staropoltavsky, Kotelnikovsky and Leninsky districts). Our studies were carried out as passive hygienic observations at medical offices of the educational institutions. Prior to the study, all prospective participants, or their parents, gave written informed consents. At the selection stage, children with chronic illnesses, affecting growth and development, were excluded from the database.

Anthropometric indicators were assessed by a standardized method using standard tools: a wooden height meter and medical lever scales.

Our results were processed using the programs Statistica 6.0, MATLAB 7 and a package of original application software for analyzing the parameters of the physical development in children and youth using the percentile method.

An advantage of analyzing physical development data via this particular method was that its application did not depend on the 
type of data array distribution function and did not require their normality. The values of length and body weight indicators were computed for the following centiles: 3, 10, 25, 50, 75, 90 and $97(\%)$. To assess the harmony of the physical development in 7-17 yo children and adolescents of the Volgograd Region based on preliminary assessment of percentile corridors and intervals of analyzed age- and gender-specific anthropometric indicators, the entire data array (4367 units) was distributed among corresponding corridor (intervals) No. 1 through 8. Hence, the first corridor corresponded to the following condition for the parameter $\mathrm{x}$ under study (body weight or height): $\mathrm{x} \leq \mathrm{C} 3 \%$, where C3\% is a $3 \%$ centile. Similarly, the second corridor corresponds to the inequality: $\mathrm{C} 3 \%<\mathrm{x} \leq \mathrm{C} 10 \%$. The other centile corridors were assigned in a similar manner.

The method permitted us to calculate percentile corridors for each age and gender. Then, using the corridor numbers, we could analyze the harmony of the physical development in the studied population of boys or girls simultaneously for the entire data array. Despite the fact that the boundaries of centile corridors increased with a child age, the number of each centile corridor was formed by the same rules within each age. The data array consisting of these numbers (from 1 to 8 ) was subjected to further analysis. Using the Statistica 6.0 package, it was possible to estimate the amount of elements falling into a given range of number values. Actually, the concept of development harmony was formulated within the framework of described procedure [3]. To assure certainty, we introduced the following parameter values describing the physical development harmony: harmonious normal development (determined by the percentage of the body growth and weight values in percentile corridors No. 4 and 5), harmonious high development (identified by the percentage of the body growth and weight values falling into the corridor No. 7) and harmonious low development (determined by the percentage of the body growth and weight values falling into the corridor No. 2).

The development is also considered harmonious, when the difference in the corridor numbers among growth and weight does not exceed 1.

Disharmonious physical development is determined by the percentage of body growth and weight values falling into all remaining corridors, as well as when the difference among the corridor numbers is equal to, or greater than, 2 .

It is quite obvious that the manual calculation of harmony, according to the above scheme, for large data arrays (several thousand) is a very challenging task. That is why we developed a computer program for performing such data partitioning in automatic mode. The results of calculating the harmony parameter via this program are presented in the Results section.

\section{Results}

Here we present the computed values of somatometric indicators (body length, $\mathrm{cm}$, and body weight, $\mathrm{kg}$ ) in 7-17 yo school students, who were the residents of the Volgograd region (Russian Federation), obtained using the percentile method. The standard $3,10,25,50,75,90$ and 97 (\%) centiles were selected for this purpose. The array of analyzed data covered the period of 20122016. Statistical processing was conducted on a gender-related basis. Tables 1-4 demonstrate the computed boundaries of percentile corridors for somatometric indicators characterizing physical development of boys (Tables 1 and 3) and girls (Tables 2 and 4 ) at the time of the study.
Table 1. Age-related centile distribution of body lengths $(\mathrm{cm})$ for boys in Volgograd region

\begin{tabular}{lccccccc}
\hline $\begin{array}{l}\text { Age, } \\
\text { years }\end{array}$ & $3 \%$ & $10 \%$ & $25 \%$ & $50 \%$ & $75 \%$ & $90 \%$ & $97 \%$ \\
\hline 7 & 83.0 & 115.8 & 120.0 & 124.0 & 128.5 & 131.4 & 137.0 \\
8 & 92.0 & 116.2 & 124.0 & 127.1 & 131.9 & 136.0 & 139.6 \\
9 & 109.6 & 123.8 & 127.5 & 130.0 & 136.0 & 140.0 & 148.5 \\
10 & 124.8 & 128.0 & 132.0 & 137.0 & 141.4 & 146.5 & 152.0 \\
11 & 124.1 & 133.2 & 138.0 & 142.0 & 147.2 & 151.0 & 158.6 \\
12 & 117.7 & 138.6 & 144.0 & 148.1 & 154.0 & 159.0 & 166.2 \\
13 & 141.3 & 146.0 & 152.0 & 157.8 & 162.8 & 168.6 & 175.3 \\
14 & 143.6 & 151.0 & 159.0 & 164.0 & 169.2 & 175.0 & 181.2 \\
15 & 148.7 & 158.0 & 163.0 & 167.0 & 174.0 & 178.2 & 183.7 \\
16 & 153.0 & 163.0 & 169.0 & 175.0 & 179.0 & 182.0 & 187.0 \\
17 & 157.7 & 164.0 & 170.0 & 174.6 & 180.0 & 186.0 & 191.0 \\
\hline
\end{tabular}

Table 2. Age-related centile distribution of body lengths $(\mathrm{cm})$ for girls in Volgograd region

\begin{tabular}{lccccccc}
\hline $\begin{array}{l}\text { Age, } \\
\text { years }\end{array}$ & \multicolumn{7}{c}{ Body length centiles } \\
\hline 7 & 89.6 & 113.0 & 117.0 & 121.5 & 125.5 & 130.0 & 134.7 \\
8 & 94.7 & 117.2 & 122.1 & 127.0 & 132.0 & 136.0 & 139.0 \\
9 & 94.3 & 123.0 & 127.0 & 130.0 & 135.0 & 139.0 & 144.2 \\
10 & 124.0 & 127.6 & 131.0 & 135.0 & 140.0 & 145.0 & 152.0 \\
11 & 106.6 & 128.2 & 136.0 & 140.6 & 146.8 & 151.4 & 158.3 \\
12 & 121.6 & 138.0 & 144.0 & 148.0 & 155.0 & 160.0 & 163.9 \\
13 & 139.2 & 145.7 & 150.5 & 156.0 & 161.2 & 164.8 & 169.0 \\
14 & 147.4 & 152.2 & 156.3 & 160.0 & 163.0 & 168.7 & 172.0 \\
15 & 150.0 & 155.0 & 158.0 & 161.0 & 165.0 & 169.4 & 175.0 \\
16 & 150.0 & 156.0 & 160.0 & 164.0 & 168.0 & 175.0 & 176.2 \\
17 & 153.0 & 157.0 & 161.0 & 165.0 & 169.0 & 173.0 & 176.0 \\
\hline
\end{tabular}

Table 3. Age-related centile distribution of body weights $(\mathrm{kg})$ for boys and male youth in Volgograd Region

\begin{tabular}{lccccccc}
\hline $\begin{array}{l}\text { Age, } \\
\text { years }\end{array}$ & $3 \%$ & $10 \%$ & $25 \%$ & $50 \%$ & $75 \%$ & $90 \%$ & $97 \%$ \\
\hline 7 & 18.9 & 20.1 & 22.0 & 24.0 & 27.0 & 30.0 & 35.0 \\
8 & 19.4 & 21.3 & 23.2 & 25.0 & 29.0 & 34.4 & 43.0 \\
9 & 20.0 & 24.0 & 25.0 & 28.0 & 33.0 & 37.9 & 44.5 \\
10 & 23.4 & 25.5 & 28.1 & 32.0 & 38.0 & 44.0 & 48.0 \\
11 & 24.2 & 27.3 & 31.0 & 36.0 & 41.0 & 46.2 & 57.8 \\
12 & 25.0 & 34.0 & 38.0 & 41.0 & 48.0 & 56.2 & 73.1 \\
13 & 34.0 & 36.3 & 41.0 & 49.0 & 54.0 & 64.3 & 70.7 \\
14 & 34.9 & 41.0 & 48.0 & 53.0 & 59.0 & 67.0 & 75.2 \\
15 & 37.5 & 43.4 & 49.7 & 57.0 & 62.0 & 70.2 & 80.0 \\
16 & 43.7 & 52.0 & 58.0 & 62.3 & 69.2 & 77.2 & 84.9 \\
17 & 47.4 & 51.9 & 59.0 & 64.1 & 71.0 & 78.1 & 85.9 \\
\hline
\end{tabular}

Table 4. Age-related centile distribution of body weights $(\mathrm{kg})$ for girls and female youth in Volgograd Region

\begin{tabular}{|c|c|c|c|c|c|c|c|}
\hline \multirow{2}{*}{$\begin{array}{l}\text { Age, } \\
\text { years }\end{array}$} & \multicolumn{7}{|c|}{ Body weight centiles } \\
\hline & $3 \%$ & $10 \%$ & $25 \%$ & $50 \%$ & $75 \%$ & $90 \%$ & $97 \%$ \\
\hline 7 & 17.3 & 19.1 & 21.0 & 23.5 & 26.3 & 30.0 & 35.0 \\
\hline 8 & 19.0 & 21.0 & 23.0 & 26.0 & 30.0 & 34.0 & 37.3 \\
\hline 9 & 20.0 & 22.9 & 24.9 & 28.0 & 31.0 & 36.0 & 44.0 \\
\hline 10 & 23.0 & 25.0 & 27.6 & 32.0 & 36.3 & 40.4 & 47.6 \\
\hline 11 & 24.6 & 28.0 & 30.0 & 35.0 & 40.0 & 47.0 & 54.0 \\
\hline 12 & 24.0 & 30.0 & 35.0 & 40.0 & 47.0 & 53.2 & 67.9 \\
\hline 13 & 32.0 & 35.7 & 41.0 & 48.0 & 53.0 & 58.6 & 69.4 \\
\hline 14 & 35.1 & 40.2 & 45.0 & 49.0 & 55.5 & 60.7 & 69.9 \\
\hline 15 & 40.7 & 44.0 & 48.0 & 53.0 & 56.0 & 61.3 & 69.3 \\
\hline 16 & 41.8 & 45.3 & 49.0 & 54.0 & 60.0 & 65.0 & 76.8 \\
\hline 17 & 45.0 & 48.0 & 50.0 & 55.0 & 60.0 & 66.0 & 75.9 \\
\hline
\end{tabular}




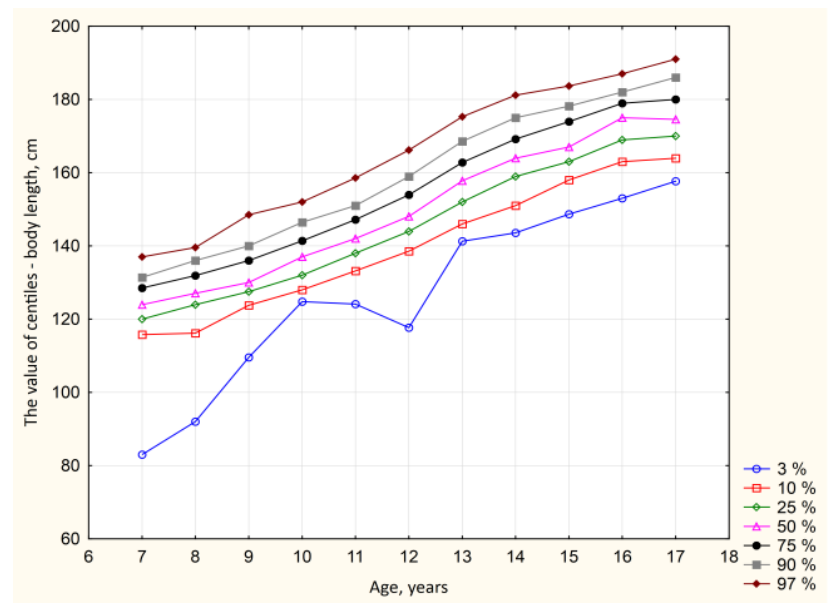

Figure 1. Dependence of body length percentile values on age in Volgograd Region boys and male youth.

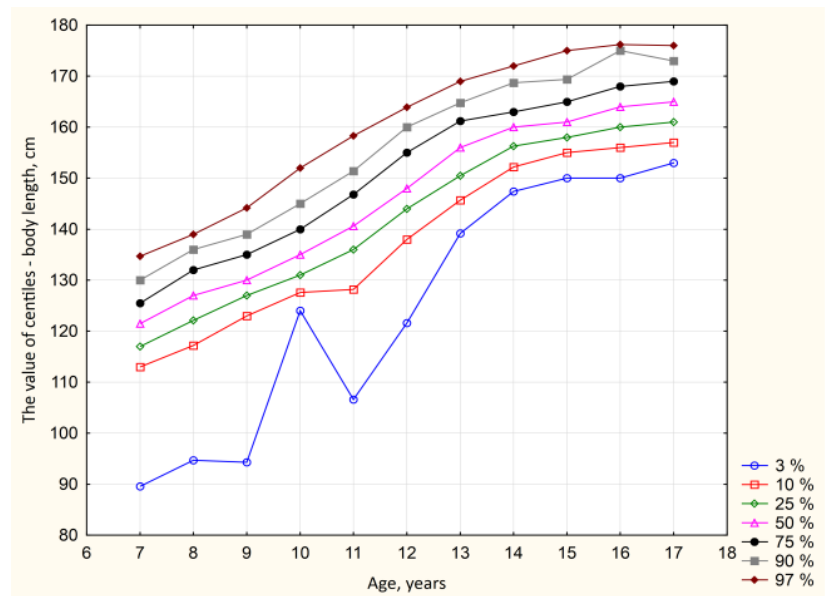

Figure 2. Dependence of body length percentile values on age in Volgograd Region girls and female youth.

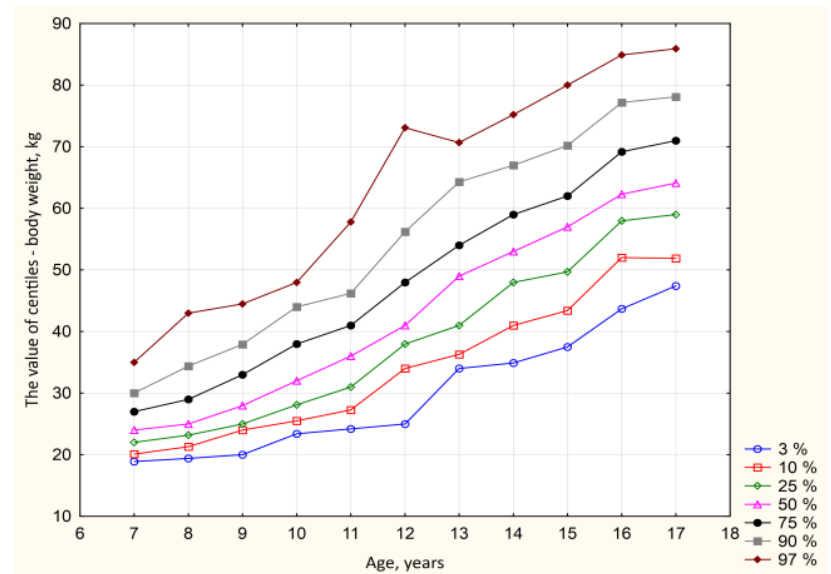

Figure 3. Dependence of body weight percentile values on age in boys and male youth of the Volgograd Region.

We discovered that, at the time of our study, the lowest values of body length were characteristic for 7 yo boys (Tables 1 and 2). In addition, in boys, body length indices for the percentile intervals 1 and 2 were lower than in girls for ages 8,12 , and $14-15$ yo. At the level of $50-90 \%$, growth indicators were equivalent for boys and girls for ages 8,9 and 12 yo. Starting from 13 yo, values of body length in boys exceed those in girls, and this dependence persists all the way until the age of 17 yo. In boys, there is a sharper growth rate of body length values, while leading dynamic characteristics are specific for the age of 13 yo. In all age groups of young men, from 14 to 17 yo, an increase in body length values was detected, while in girls, already at the age of 15-16 yo, stabilization of body length values was observed. Figures 1 and 2 offer the graphs depicting the dependence of percentile curves of the analyzed data array for the body length $(\mathrm{cm})$ of boys and girls, respectively, while Figures 3 and 4 show percentile curves for body weights $(\mathrm{kg})$ in boys and girls. Percentile curves are presented in the form of linear diagrams reflecting dynamic processes of value changes in analyzed parameters, and distribution of examined children and adolescents among age-and-gender groups.

The graph at the Figure 2 shows that in girls, the values of all centiles for the body length parameter change gradually and progressively until the age of 9 yo, while at the age of 10 yo, a very noticeable maximum of the $3 \%$ centile curve is observed. From the age of 11 yo, we observe the beginning of the body length growth rate acceleration. By 12 yo, indicators show progressive growth. At the age of 15 yo, girls have stabilized growth rates. Body length values, corresponding to the $3 \%$ centile in girls, pursue the following trend: intensive growth acceleration begins at 9 yo and continues until the age of 13 yo. In boys, the values of centiles for the body length parameter are as follows: at 7-10 yo they are lower than in girls, at 11 yo, they are ahead of girls, at 12 yo, the values of all centiles of body length in boys and girls are virtually identical, and then from 13-17 yo, the values of body length centiles in boys are ahead of the girls again (Figure 1). It should be noted that in Volgograd Region boys, body length growth does not stop at the age of 17 yo. The results of the distribution of age- and gender-specific values of body weights in boys and girls of the Volgograd Region in percentile intervals are presented in Tables 3 and 4.

As clear from Table 3, percentile characteristics of the body weight values in 7,9 , and 10 yo boys are ahead or equivalent to the girls' indicators. Body weight in 8 yo boys is particularly noteworthy, since, at the level of $25-75 \%$ centiles, their of body weight values are lower than in girls.

In all age groups, body weight values at the level of $75-97 \%$ in boys are ahead of those in girls. At the level of $3 \%$ and $10 \%$, they are behind the indicators for girls at the age of 11,13 and 15 yo; at the level of $3 \%$ they are also behind the values for 14 yo girls. At 12-13 yo, for all centiles, the values for boys are ahead or equivalent to those of girls. At 16-17 yo, body weight values in boys and male youth are ahead of those in girls for all centiles. We discovered that for body weight values, as well as for the body length, it was possible to distinguish the specificities of the dynamic changes in two boundary centiles: $3 \%$ and $97 \%$. Local extrema were also observed here for 12 and 13 yo boys, while body weight values for other centiles showed a smoother growth.

In girls, a steep increase in body weights occurred at the ages of 12 yo ( 25 to 97 centiles) and 13 yo ( 3 to 97 centiles). Then, some stabilization of indicators took place until the age of 15 yo. At 16 17 yo, body weight values started behaving erratically.

Figures 3 and 4 present the graphs of the age dependence of centiles on the body weight values - in school students of the Volgograd Region. The graphs show that the dynamic characteristics of body weight in young boys have more pronounced changes: they diverge more strongly in values in accordance with age. 


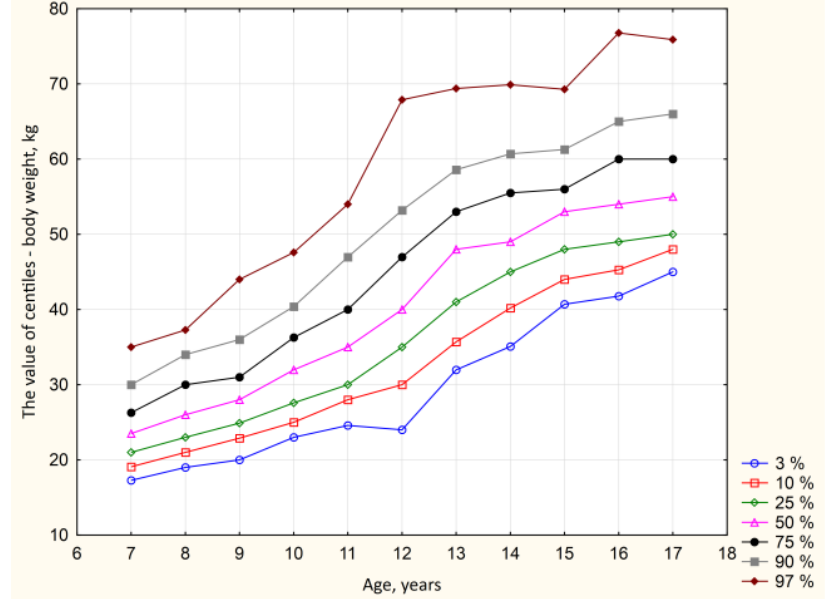

Figure 4. Dependence of body weight percentile values on age in girls and female youth of the Volgograd Region.

Table 5. Results of the frequency analysis of harmony parameter for boys in Volgograd Region

\begin{tabular}{lcccc}
\hline & Count & Cumulative & Percent & Cumulative \\
\hline 0 & 625 & 625 & 30.40 & 30.40 \\
1 & 162 & 787 & 7.88 & 38.28 \\
2 & 1088 & 1875 & 52.92 & 91.20 \\
3 & 181 & 2056 & 8.80 & 100.00 \\
Missing & 0 & 2056 & 0.00 & 100.00 \\
\hline
\end{tabular}

Table 6. Results of the frequency analysis of harmony parameter for girls in Volgograd Region

\begin{tabular}{lcccc}
\hline & Count & Cumulative & Percent & Cumulative \\
\hline 0 & 820 & 820 & 35.48 & 35.48 \\
1 & 163 & 983 & 7.05 & 42.54 \\
2 & 1149 & 2132 & 49.72 & 92.25 \\
3 & 179 & 2311 & 7.75 & 100.00 \\
Missing & 0 & 2311 & 0.00 & 100.00 \\
\hline
\end{tabular}

Tables 5 and 6 present the results of a frequency analysis of the harmony parameter for boys and girls. They imply the relationship between the harmonious and disharmonious physical development of children and adolescents in Volgograd Region. The corresponding frequencies are presented in Figures 5 and 6 . The analysis and resulting recommendations are given in the Discussion section.

\section{Discussion}

An analysis of the study results on somatometric indicators in boys, girls and youth of both genders in the Volgograd Region, conducted via the percentile method, revealed specific features. For example, we established that the rate of physical development in children and adolescents of the Volgograd Region changed as compared with conventional options for the development of Russian children and youth in the second half of the 20th century $[3,4]$.

Unlike classical patterns (when height, body weight and chest circumference from birth to puberty are on average greater in boys than in girls), Volgograd boys have centiles for the body length parameter from 7 to 10 yo lower than girls. At 11 yo, boys are longer than girls. At 12 yo, the values of all centiles of body length for boys and girls were virtually the same, and then, from
13-17 yo, the values of centiles for body length in boys were once again ahead of girls. It was established that the period of growth and development acceleration in contemporary population of examined children and adolescents in Volgograd Region was on average 1-2 years ahead of the peers in previous generations, thus falling onto $11-12$ yo for girls and 13 yo for boys. These findings matched our own earlier data [5], as well as the results by N.V Efimova \& I.V. Mylnikova [6], and V.O. Karandasheva \& L.I. Grechkina [7]. In girls, dynamic indicators of growth changes were more stable and closer to conventional patterns, which was consistent with the data by S.R. Ermolaeva \& R.M. Khayrullin [8].

Comparison of the development characteristics in school students of the Volgograd Region with the data from centile tables of A.V. Mazurin \& I.M. Vorontsov has also showed the presence of specific deviations [3]. Thus, it has been established that at present, the range of indicators in children and adolescents of the Volgograd Region became wider, because at the level of centile 3 lower parameter values have been recorded, while at the level of centile 97, they have been higher. It was found that in girls, indicators in younger age groups were lower at the levels of $3-25 \%$ until the age of 11-12 yo. Then they were beginning to exceed the parameters of peers in previous generations, reaching the greatest differences at $97 \%$. In boys, advance in comparison with the peers of previous generations was already recorded from the level of $3 \%$ at the age of 9 yo and remained in nearly all age groups, reaching the greatest differences at the level of $97 \%$ at $14-17$ yo. Relative stabilization of indicators in contemporary Volgograd school students compared with peers falls on the age of 9-11 yo [3]. It was also shown that, especially in older age groups, the majority of adolescents in the Volgograd Region have increased body weights. Currently, it is also typical for some regions of Russia (St. Petersburg, Voronezh Region, Tomsk Region, etc.) [9, 10, 11], United States and Latin American countries $[12,13]$. In general, these shifts are in line with the global trends: an increase in the numbers of overweight and obese children. What is important is an established connection between deviations in physical development in childhood and the state of health in adulthood [8, 14]. In addition, such deviations undergo other changes as compared with the data from previous generations: they are more widespread in both girls and boys, although in boys they are more dynamic. Girls are characterized by smoother changing and more stable indicators in comparison with the data on the peers from previous generations, both in terms of body length and weight. It should be noted that such conclusions were made on a significant array of experimental data (4367 people), which allowed us regarding identified patterns as statistically representative.

A comparison of anthropometric indicators in adolescents of the Volgograd Region with the data for the youth living in northern territories of the Russian Federation (Irkutsk Region) [6], revealed at the present stage the differences in both body length and weight. Thus, at the level of $3 \%$ of the analyzed distribution in all age-and-gender groups from 11-17 yo (except for the 13 yo boys), the body length Volgograd Region youth was lower than in their northern peers. Volgograd Region girls, in their growth indicators, compared with the residents of Irkutsk Region, fall behind at the age of 11-14 yo. At 15 yo, the total match between the both groups was revealed, and from 15-17 yo Volgograd girls were ahead for all analyzed centile boundaries: 3, 25, 50, 75, 97(\%). Male adolescents of the Volgograd Region fall behind their counterparts from Irkutsk at $11-15$ yo in terms of growth indicators, and then they get ahead. 


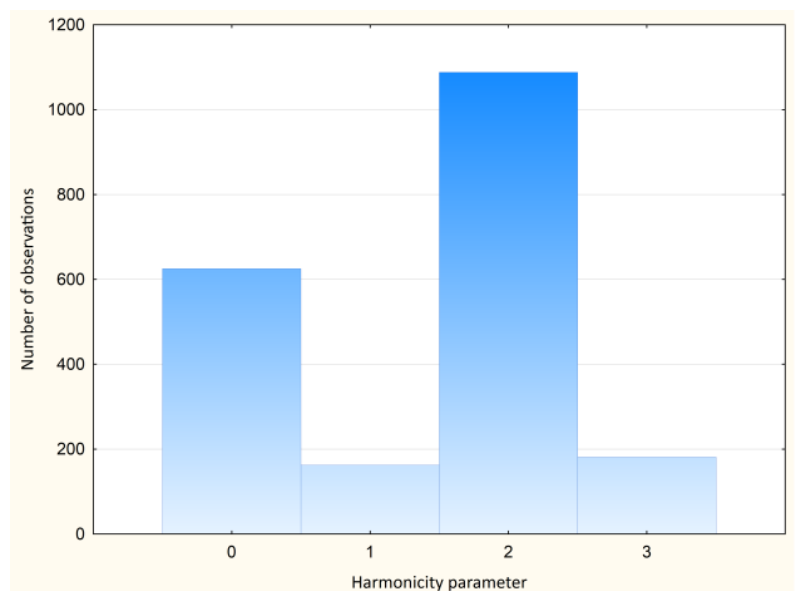

Figure 5. Histogram of the harmony parameter of the physical development in boys and male youth of the Volgograd Region. Harmony parameter: 0 - disharmonious, 1 - harmonious low; 2 - harmonious normal; 3 - harmonious high.

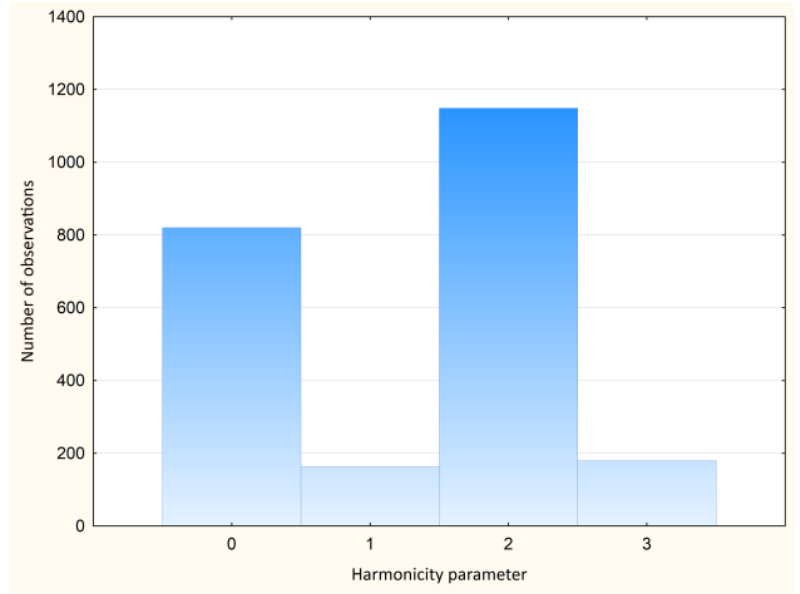

Figure 6. Histogram of the harmony parameter of the physical development in girls and female youth of the Volgograd Region. Harmony parameter: 0 - disharmonious, 1 - harmonious low; 2 - harmonious normal; 3 - harmonious high.

In terms of body mass, boys and male youth of Volgograd Region also fall behind in the age groups of 11-12 and 14-15 yo, whereas, in the age groups of 13,16 and 17 yo, the indicators are higher. Girls have similar trends, but at the age of $13-17$ yo an approximate equality of indicators is recorded at the levels of 2550 centiles. The revealed patterns are largely consistent with the data showing that the body weights of children and adolescents living in the northern regions (Tomsk Region, Magadan) are significantly higher than in entire Russia, or in its Central areas) [8, 9].

Hence, we state that the values of indicators in children and adolescents of Volgograd Region, forming the boundaries of centile groups, are currently dependent on their age and gender and consistent with unevenness and heterochrony of the physical development rates in children and adolescents living in various regions of the Russian Federation [4, 7].
An analysis of the physical development harmony in Volgograd Region children and youth conducted via percentile method showed that $69.6 \%$ of boys and $61.7 \%$ of girls had harmonious development. At the same time, harmonious normal development was observed in $52.9 \%$ of boys, while harmonious high and harmonious low were characteristic for $8.8 \%$, and $7.9 \%$, respectively. Disharmonious development was present in $30.4 \%$ of boys. For girls, the indicators were as follows: harmonious normal, harmonious high, harmonious low and disharmonious types of a physical development were found in $46.5 \%, 6.2 \%, 9.0 \%$ and $38.4 \%$, correspondingly. Our results compared against the data of other authors [6] revealed their similarity. However, some discrepancies were quite noticeable. For example, in Irkutsk Region, $59.4 \%$ of boys and $49.6 \%$ of girls were found to have harmonious physical development. This finding substantiated the need for regional monitoring of the growth and development in children and adolescents.

Despite indicated advantages of the percentile method and important findings, it has certain limitations like any other technique. They are related to impossibility of applying parametric statistical analysis to the data.

\section{Conclusion}

For the first time in history, an analysis of the physical development parameters in over four thousand children and adolescents of the Volgograd Region was carried out using the percentile method. The ratio of harmonious / disharmonious physical development (in \%) was established: 70/30 among boys, and 62/38 in girls.

Contemporary characteristic features of anthropometric parameter values were revealed: the most pronounced changes in growth rates were observed in boys: the boundary values of the traits had larger ranges and, starting from the age of 13 yo, they were 1-2 years ahead of their peers from previous generations; by the age of 17 yo, their body length growth did not end. In girls, dynamic indicators of changes in body height and weight were more stable and close to conventional patterns. Therefore, identified features of physical development necessitated the need for regional monitoring of the growth and development in children and adolescents, as well as the feasibility of developing and systematically updating regional standards.

\section{Conflict of interest}

Conflict of interest is not stated, since the authors of this study independently formulated the research objective, developed appropriate methods, developed original computer programs, and performed all required computations.

\section{Ethical approval}

All procedures performed in studies involving human participants were in accordance with the ethical standards of the institutional research committee and with the 1964 Helsinki declaration and its later amendments or comparable ethical standards.

\section{References}

1. Velichkovsky BT, Baranov AA, Kuchma VR. Growth and development of children and teenagers in Russia. Annals of the Russian Academy of Medical Sciences 2004; (1): 43-45. Russian. https://elibrary.ru/item.asp?id=17037918. 
2. Kuchma VR, Skoblina NA, Milushkina OYu, Gudinova ZhV, Bokareva NA, Gavryushin My, et al. Physical development of children and adolescents of the Russian Federation: tutorial. Volume VII. Moscow, Russia: Litterra, 2019; 176 p. Russian. https://elibrary.ru/item.asp?id=37004445.

3. Vorontsov IM, Mazurin AV. Propaedeutics of childhood diseases. St. Petersburg, Russia: Foliant Publishing House LLC, 2009; 1008 p. Russian. https://elibrary.ru/item.asp?id=19545994.

4. Kuchma VR. Hygiene of children and adolescents. Moscow, Russia: Geotar-Media, 2008; 480 p. $\quad$ Russian. https://elibrary.ru/item.asp?id=19540924.

5. Latyshevskaya NI, Yatsyshen VV, Davydenko LA, Yatsyshena TL. The dynamics of the physical development of children and adolescents in the city of Volgograd in 1976-2016. Hygiene and Sanitation 2018; 97(9): 844-847. Russian. http://doi.org/10.18821/0016-9900-2018-979-844-847.

6. Efimova NV, Mylnikova IV. Description of the physical development of modern adolescents in industrial cities. In: Physical development of children and adolescents of the Russian Federation. Volume VII. Moscow, Russia: Litterra, 2019: 42-50. Russian. https://elibrary.ru/item.asp?id=37004445.

7. Karandasheva VO, Grechkina LI. Comparative characteristics of physical development observed in schoolchildren living in different regions of Russia. Vestnik Severo-Vostochnogo Gosudarstvennogo Universiteta 2018; $\quad$ (30): 32-37. Russian. https://elibrary.ru/item.asp?id=36479314.

8. Ermolaeva SV, Khairullin RM. Features of the physical development of schoolchild of the Ulyanovsk region. Morphological Newsletter 2016; 24(3): 95-98. Russian. https://elibrary.ru/item.asp?id=27165955.

9. Gritsinskaya VL, Nikitina IL. Modern aspects of evaluation of physical development of schoolchildren in the megapolis. Medical Council 2017; (19): 40-43. Russian. https://doi.org/10.21518/2079-701X-201719-40-43.

10. Nastausheva TL, Zhdanova OA, Minakova OV, Logvinova II, Ippolitova LI. Comparative characteristics of children physical development in Voronezh Region of the Russian Federation for 15 years. Russ Open Med J 2017; 6(1): e0102. https://doi.org/10.15275/rusomj.2017.0102.

11. Deyev IA, Kolomeyets IL, Kamaltynova YeM, Kulikov YeS, Levko AN, Fyodorova OS, et al. Features of the main indicators of the physical development of teenagers in the Tomsk region. Bulletin of Siberian Medicine 2015; 14(6): 40-47. https://elibrary.ru/item.asp?id=25449090.

12. Halfon N, Larson K, Slusser W. Associations between obesity and comorbid mental health, developmental, and physical health conditions in a nationally representative sample of US children aged 10 to 17. Acad Pediatr 2013; 13(1): 6-13. https://doi.org/10.1016/j.acap.2012.10.007.

13. McCormick EV, Dickinson LM, Haemer MA, Knierim SD, Hambidge SJ, Davidson AJ. What can providers learn from childhood body mass index trajectories: a study of a large, safety-net clinical population. Acad Pediatr 2014; 14(6): 639-645. https://doi.org/10.1016/j.acap.2014.06.009.

14. Thompson R, Flaherty EG, English DJ, Litrownik AJ, Dubowitz $H$, Kotch $\mathrm{JB}$, et al. Trajectories of adverse childhood experiences and selfreported health at age 18. Acad Pediatr 2015; 15(5): 503-509. https://doi.org/10.1016/j.acap.2014.09.010.

Authors:

Valery V. Yatsyshen - DSc, Professor, Professor, Institute of Priority Technologies, Volgograd State University, Volgograd, Russia. https://orcid.org/0000-0003-4185-2333.

Tatyana L. Yatsyshena - PhD, Associate Professor, Associate Professor, Department of Hygiene, Volgograd State Medical University, Volgograd, Russia. https://orcid.org/0000-0001-6304-6565. 